\section{Physics before big physics}

\section{Laurie M. Brown}

Rabi: Scientist and Citizen. By John S Rigden. Basic Books:1987. Pp.302. \$21.95. Alvarez: Adventures of a Physicist. By Luis W. Alvarez. Basic Books:1987. Pp. 292. \$19.95.

IsIDOR Isaac Rabi and Luis W. Alvarez are both renowned experimental physicists, and are among the American science Nobel Laureates who rendered important public service during and after the Second World War. Rabi was largely responsible for the establishment in 1947 of Brookhaven National Laboratory on Long Island, New York - the first large national laboratory to be managed by a consortium of universities - and he has also been an international scientific statesman. At the General Assembly of UNESCO in Florence in 1950, he proposed, on behalf of the United States, a resolution calling for the establishment of a European physics laboratory, which was officially realized in 1952 as the European Laboratory for Nuclear Research (CERN) at Geneva. Alvarez's varied and adventurous career has included the development of nuclear weapons and of inventions important in military and civil aviation. An experienced pilot, he served as scientific observer on the B-29 bomber Great Artiste when it accompanied the Enola Gay on its fateful mission over Hiroshima on 6 August, 1945.

Rabi came from a penurious and unscientific, though culturally rich, background, while Alvarez's family was affluent and well-educated (his father, Walter, was a physiologist and a famous physician). Rabi was born in 1898, Alvarez in 1911 , but Alvarez matured rapidly as a scientist and, at the outbreak of the Second World War, both men were in position to accept important tasks. Rabi became associate director of the Radiation Laboratory at the Massachusetts Institute of Technology under Lee DuBridge, working with British scientists, the military and industry on the development of radar devices. Later in the war, at Los Alamos, he counselled his friend Robert Oppenheimer, especially on personnel problems that baffled Oppenheimer. Alvarez worked at the Radiation Laboratory in a more direct way than Rabi, inventing radar systems for tracking submarines, for blind ground-control approach of landing aircraft (GCA), for early warning (MEW) and for blindbombing (EAGLE). In 1943 he moved, first to Chicago to work with Fermi at the Metallurgical Laboratory, a cover name for the atomic bomb project, and then to
Los Alamos, where he applied his ingenuity to the implosion problem. Their experiences enabled both Alvarez and Rabi to assume positions of authority after the war, and they were among those who helped to transform physics research into big science - a milieu in which neither of them would be very satisfied to work nowadays.

The two books under review belong to a series, sponsored by the Alfred P. Sloan Foundation, which is intended to be essentially autobiographical. In that spirit, Rabi and his wife Helen collaborated closely with John S. Rigden, who is a well-known physicist at Washington University in St Louis, a scientific historian and the editor of the American Journal of Physics. Some of the material in his book was included in Jeremy Bernstein's article about Rabi that appeared in the New Yorker in 1970. But here Rigden provides welcome (though unobtrusive) historical documentation, so that we know not only what Rabi said, but when he said it, and to whom. Both Alvarez's and Rigden's writings are thoughtful and fresh. There is much insight in them, social as well as scientific, more explicitly in the Rabi book, more inferentially in Alvarez's. Both are accessible, and they deserve a wide audience.

Rabi's life is the stuff of which American urban legends are made. He was born Israel Isaac Rabi in Rymanow, in Galicia,
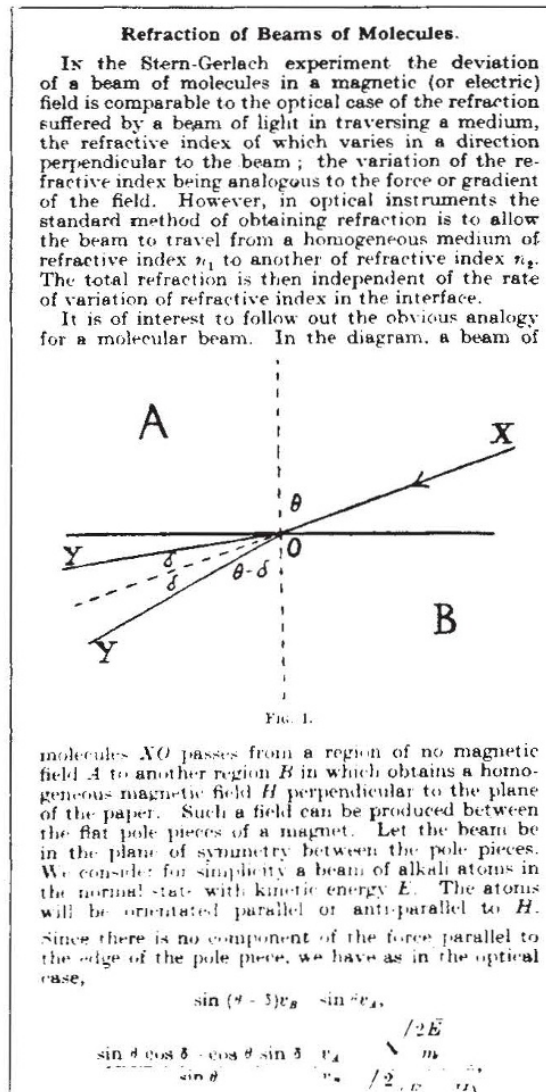

Seminal paper - the opening half of Rabi's first report (Nature 123, 163; 1929) of work that was to win him a Nobel Prize. now Poland, a mostly Jewish town where Rabi, on a visit in 1968 , could find no vestige of Jewishness - even the gravestones had been levelled. (The name Israel later became 'Izzy', and turned into Isidor.) Rabi's father David, unskilled, and uneducated except in the Orthodox Jewish tradition, emigrated to the United States and soon sent for his wife Sheindel and their infant son. David Rabi worked at menial tasks, and the family lived in a Jewish ghetto, the fabled Lower East Side of Manhattan, full of saloons and synagogues, and thronged by prostitutes and criminals, as well as the pious. Home was two rooms, occupied by Isidor, his sister Gertrude, the parents and two boarders! There were visitors, whose discussions in Yiddish were often political, and generally socialist in tenor. Young Rabi developed rapidly in this environment - he could read the Yiddish newspaper before he started school at the age of five.

When Rabi was nine, the family moved to Brooklyn, where they lived in the back of a small grocery store. The whole family helped to run the store, and the money drawer was open to them all. Rabi says, "I didn't know we were poor". He discovered the local public library, and after reading all the children's books started on the adult section with a book on astronomy. Reading about the Copernican system was a turning point in his life. Rabi has always admired, and has had an emotional need for some coherent, allencompassing intellectual system. Thus he moved from Orthodox Judaism to Marxist Socialism to Modern Science. His socialist views were abandoned, he says, when he looked around at his classmates in high school and thought, "These people could never run a country"

Rabi chose to attend Manual Training High School, walking three miles through gang-infested streets to get there, instead of a closer and higher quality school in a Jewish neighbourhood, in an attempt to escape from his Jewishness: "I had very definite notions of being an American in a broader sense". However, when he graduated in 1916 and went to Ithaca in upstate New York to attend Cornell University he "encountered a lot of discrimination and anti-Jewish sentiment". Likewise, when he graduated as a chemistry major three years later, neither he nor his few Jewish classmates were offered jobs in industry, although other chemists were "snapped up". There followed three years of unemployment, spent living at home and reading in the Public Library. Despairing of a job, he returned to Cornell as a graduate student in chemistry but discovered that the part of chemistry that he really enjoyed was called physics.

After a year, he left for Columbia University, where he invented an elegant null method for determining the magnetic susceptibilities of crystals. He also studied 
the new quantum mechanics of 19251926 , and with Ralph de Kronig solved the Schrödinger equation for the symmetrical top. After getting his PhD and marrying, he gave up the teaching job he had held at the City College of New York and went to Europe. Although he had not troubled to write ahead, in that golden age of physics he was able to visit Erwin Schrödinger at Zurich, Arnold Sommerfield at Munich and Niels Bohr in Copenhagen. To Rabi's surprise, Bohr sent him, together with Yoshio Nishina from Japan, to Wolfgang Pauli in Hamburg. This was another turning point for Rabi, not because of Pauli, but because Otto Stern challenged Rabi to perform a molecular beam experiment that Rabi (then thinking of himself as a theorist) had proposed. In brief, the dénouement of this story is the following. In 1944, when the first Nobel Prizes in five years were announced, the physics prizes were awarded for molecular beam experiments; the 1943 prize went to Stern, and that for 1944 to Rabi "for his resonance method for recording the magnetic properties of atomic nuclei". Rabi's work forms the trunk of a whole tree of important scientific advances, many of them made by his students and coworkers, as Rigden points out.

Luis Alvarez never had to bother about social acceptance. His book is full of the pleasure that he takes in associating with influential people and in the perquisites of power and wealth. His friends are business and military figures, as well as the brilliant and honoured scientists he knows. He reserves his greatest admiration for activists, for inventors and organizers. He has flown a plane for over 1,000 hours, and he says that he thinks of himself "as having had two separate careers, one in science and one in aviation" and that he has found the two "almost equally rewarding".

Like other experimentalists of the school of his mentor, Ernest Lawrence, Alvarez feels strongly that theories of physics are not meant so much to be tested as challenged. When he did nuclear physics in the 1930s, he studied carefully a set of review articles that made up what came to be called (Hans) "Bethe's Bible", about which he remarked later, "If [Bethe] said a phenomenon would never be observable, I wanted to prove him wrong". Among his pre-war achievements, he demonstrated electron capture by atomic nuclei and the decay of $\mathrm{H}^{3}$ into $\mathrm{He}^{3}$. (It had been thought that $\mathrm{H}^{3}$ was more stable than $\mathrm{He}^{3}$.) In 1968 he received the Nobel Prize for developing the hydrogen bubble chamber and associated analytical techniques that allowed the discovery of many resonance states of strange particles.

In the book, Alvarez offers his views on the present status of the fields of physics in which he has been most prominent.

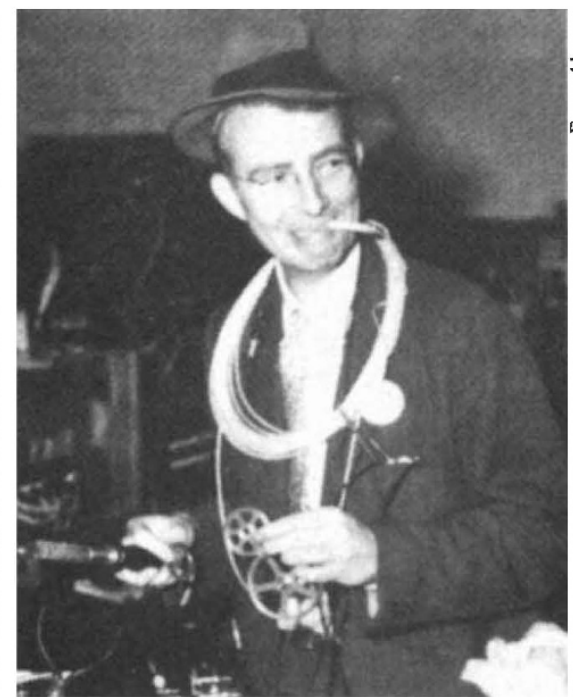

End of a phase - Luis Alvarez on his last day at the MIT Radiation Laboratory, September 1943.

"There is no way", he says, "that a person with my personal qualities could go either into nuclear physics or particle physics at the present time". One of his criticisms is that experiments are carried out by such large groups, reaching to hundreds of people, that he would miss the pleasures of essential participation and of individual recognition. His second criticism is what he considers to be an undue influence of theorists in making funding and scheduling decisions at particle accelerators. About experiments that merely check what "every theorist was convinced" of, such as the discovery of the $W$ and $Z$ particles at CERN, he asks, "What was really learned?"

Alvarez and Rabi both witnessed the first nuclear bomb test at Alamagordo, and found it to be a profound experience. Both are convinced (as one might expect of good establishment scientists) that it was morally justified not only to make the bombs but to drop them on Japan because, they argue, on balance Japanese and Allied lives were saved by those acts. (I have never been comfortable with this quantitative approach to mortality or morality.) Alvarez and Rabi differed, however, after the Soviet Union's first nuclear explosion on 29 August, 1949, Alvarez joining Lawrence and Edward Teller in proposing a crash programme to build the "Super" (as the earlier proposed version of the hydrogen bomb was called), while Rabi concurred with the rest of the General Advisory Committee to the Atomic Energy Committee, headed by Oppenheimer, that such an action was unjustified at the time. It would be unfair to try to summarize their reasons here. At the hearing which led to the suspension of Oppenheimer's security clearance in 1954, Rabi appeared in his defence, while Alvarez testified that he thought Oppenheimer's reasoning on the Super had been faulty, but did not question his loyalty to the United States.

Rabi's main contributions, other than his science, may turn out to have been in influencing Eisenhower to establish a strong science advisory presence in the White House and his efforts on behalf of international control of atomic energy (which led to the First International Conference on the Peaceful Uses of Atomic Energy in August 1955). Alvarez himself feels that he may be best remembered for having proposed, with his geologist son Walter, the theory that the dinosaurs and some other species of animal became extinct as the result of the collision of the Earth with an asteroid about ten kilometres in diameter, causing huge clouds of dust to obscure the Sun. This has led some physicists to consider the possibility that a nuclear war might give rise to similarly large dust clouds and result in the socalled "Nuclear Winter". If this should lead to rethinking on the part of those who still consider nuclear war as a survivable alternative for mankind, then Luis and Walter Alvarez may have, indirectly, made a notable contribution to world peace.

Laurie M. Brown is Professor of Physics and Astronomy at Northwestern University, Evanston, Illinois 60201, USA. Twenty-five years after I.I. Rabi, he attended Manual Training High School in Brooklyn and Cornell University.

\section{The Quantum and Beyond} William M. Honig

Western Australian Institute of Technology, Perth, 6102, Australia.

MAX JAMMER'Thought-provoking important newideas on fundamental issues, intellectually courageous'

FRANCO SELLERI 'Inspiring book ...for the deeper understanding of subatomic reality on a causal basis'

EMILIO PANARELLA 'Wealth of new concepts, aesthetic beauty, powerful new analytic tools...an intellectual treat'

MAURICE SURDIN 'A courageous effort to go beyond the established' LUDWIK KOSTRO 'Hydrodynamical models offer many possibilities' SIMON PROKHOVNIK'Useful and intelligible view of $\mathrm{E}=\mathrm{hf}$ via photex model'

$\$ 17.50$ Soft Cover, $\$ 25$ Hard Cover 317 pages, 44 Illus, Postage $\$ 3.50$.

Philosophical Library, Inc. 200W.57 St., NY, 10019, NY 